\title{
Diet Sugar-Free Carbonated Soda Beverage, Non-Caloric Flavors Consumption, and Diabetic Retinopathy: Any Linkage
}

\author{
Hyder Mirghani iD \\ Naif Alali ${ }^{1,2}$ \\ Hani Albalawi ${ }^{2}$ \\ Ruba ALselaimy ${ }^{3}$ \\ 'Internal Medicine and Endocrine, \\ Medical Department, Faculty of Medicine, \\ University of Tabuk, Tabuk, Kingdom of \\ Saudi Arabia; ${ }^{2}$ Ophthalmology \\ Department, Faculty of Medicine, \\ University of Tabuk, Tabuk, Kingdom of \\ Saudi Arabia; ${ }^{3}$ Ophthalmology \\ Department, King Saud University, \\ Riyadh, Saudi Arabia
}

Purpose: Assessing diabetic retinopathy (DR) risk factors and daily nutrition habits are vital for prevention. This study aims to evaluate the relationship between diet soda cans, nonnutritive sweetener consumption, and diabetic retinopathy.

Patients and Methods: A cross-sectional study was conducted among 200 patients attending a diabetes center in Tabuk City, Saudi Arabia, from September 2019 to July 2020. A structured questionnaire was used to collect patients' demographic factors, and DR risk factors including the use of diet soda, non-nutritive sweeteners, and exercise habits. Dilated fundus eye examination was done to detect any diabetic retinopathy. A blood sample was taken for measuring glycated hemoglobin to assess the degree of glycemic control.

Results: The participant's age was $50.74 \pm 13.51$ years, and the duration since the diagnosis of diabetes was $9.99 \pm 6.97$ years, body mass index was $27.28 \pm 4.68$, and $\mathrm{HbA1c} \%, 8.50$ \pm 1.61 ), the patients used to consume $1.31 \pm 1.57$ diet soda cans/week, and $1.06 \pm 1.39$ artificial sweeteners/sachet/day. DR was found in 33\%. Diet sugar-free carbonated soda beverage was associated with poor glycemic control and retinopathy, while non-caloric flavor consumption was associated with obesity $(\mathrm{P}-\mathrm{value}<0.05)$. No association was evident regarding other factors (P-value $>0.05)$.

Conclusion: Diet sugar-free carbonated soda beverage was associated with higher HbA1c and retinopathy, while non-caloric flavor consumption was associated with obesity. No association was evident regarding other factors. Further larger multicenter studies are needed.

Keywords: non-caloric flavors, carbonated soda beverage, diabetic retinopathy

\section{Introduction}

Diabetes mellitus is a major health problem; the disease is rapidly growing with great morbidity and mortality that mainly from its vascular complications. Currently, around 350 million people worldwide have diabetes mellitus, and this number expected to increase because of an aging population globally, an increased prevalence of obesity, as well as sedentary lifestyles. ${ }^{1}$ The Kingdom of Saudi Arabia is among the countries with the highest prevalence. It is estimated that $23.7 \%$ are suffering from this morbid disease, with more than one-third being affected by diabetic retinopathy (DR). ${ }^{2,3} \mathrm{DR}$ is considered a primary vascular complication of diabetes mellitus on the retina blood vessels; more specifically, it represents microvascular end-organ damage because of uncontrolled diabetes and it
Correspondence: Hyder Mirghani Faculty of Medicine, University of Tabuk, PO Box 3378, Tabuk, 5I94I, Saudi Arabia Tel +966569344569

Email s.hyder63@hotmail.conm 
is usually asymptomatic in its early stages. When left untreated, DR may substantially affect vision and even can lead to blindness. DR is the leading cause of blindness among the working-age group worldwide. ${ }^{4}$ The prevalence and risk factors of DR are not uniform and differ widely by geographical areas; however, among well known, its risk factors are hypertension, uncontrolled diabetes mellitus, long duration of diabetes, smoking, gender, obesity, dyslipidemia, and others. ${ }^{5}$ The Wisconsin Epidemiologic Study of Diabetic Retinopathy (WESDR) Cohort showed that after 20 years of diabetes mellitus, nearly all patients with type 1 and $60 \%$ of patients with type 2 show some degree of retinopathy. ${ }^{6,7}$ By 2030, it is estimated that around 191 million people will have some degree of diabetic retinopathy, and approximately more than 50 million will have vision-threatening diabetic retinopathy if no urgent intervention is taken. ${ }^{8}$

Nowadays, with more and more diet habits changes, we can see shifting toward healthy food using non-caloric sweeteners and diet soda beverages instead of regular soda. The beginning of diet soda was in 1952 when the local company in Brooklyn, New York launched a sugarfree ginger ale; it was designed for people with diabetes; since that time, diet soda consumption became more and more popular with many different flavor production.

To our best of knowledge, no researchers have assessed the association of diet soda soft drink and non-nutritive sweeteners in the Kingdom of Saudi Arabia as risk factors of DR. Thus, we conducted this research to assess any relationship between diet soda soft drink and non-nutritive sweeteners and the rate of diabetic retinopathy.

\section{Patients and Methods}

This is a cross-sectional study conducted among 200 adult patients with diabetes mellitus attending the diabetes center in King Fahd Specialty Hospital, Tabuk City, Saudi Arabia, during the period from September 2019 to July 2020. All the patients aged above 18 years were included; children and pregnant women were excluded. The participants were enrolled from the outpatient; one clinic will be selected randomly from the three clinics. The data collector came to the center one day/week. Thus, the sample size was limited to the time of the study period. A structured questionnaire was used to collect demographic data, the duration of diabetes mellitus, diet soda (cans/week), body mass index, artificial sweeteners (sachet/day), and symptomatic hypoglycemia in the last year, hypertension, smoking, if on regular exercise, family history of diabetes, and anti-diabetic medications. A blood sample was taken for the glycated hemoglobin estimation. All the participants signed written informed consent, and the ethical committee of the University of Tabuk approved the research (ref. number, UT-93-1-2020, date, 27/1/2020).

For this research, the following definitions were adopted:

Diabetic retinopathy: either non-proliferative diabetic retinopathy signs (retinal hemorrhage in all form flameshaped or blot, soft or hard exudate, venous beading, vein looping, intraretinal microvascular abnormalities (IRMA) and others) or proliferative diabetic retinopathy signs (neovascularization of the optic nerve disc, neovascularization elsewhere, vitreous hemorrhage and others). ${ }^{9}$

Body mass index: obesity was defined at BMI $\geq 30$, overweight at 25-29, and a BMI of 18-25 was considered normal.

Regular exercise: Exercise for 30 minutes daily for 5 days a week.

Hypertension: If diagnosed previously with hypertension, taking anti-hypertensive drugs, or cutoff value (140/ $90 \mathrm{mmHg}$, recorded twice). ${ }^{10}$

Poor control of diabetes mellitus: A glycated hemoglobin $>8$ is regarded as poorly controlled diabetes mellitus. ${ }^{11}$

Symptomatic hypoglycemia: Fingerstick glucose of $\leq 70 \mathrm{mg} / \mathrm{Dl}{ }^{12}$

Soft drink consumption: depend on validity and reproducibility of a 145-item self-administered food frequency questionnaire (FFQ), and according to it all patients sample were asked about consumption of soft drink then divided to no consumption when using less than $1 \mathrm{can} /$ week $(375 \mathrm{~mL})$, moderate when using 1-4 cans/week, severe when using more than 5 cans/week. ${ }^{13,14}$

\section{Statistical Analysis}

The Statistical Package for Social Sciences (SPSS, version 20, New York) was used during the analysis of the collected data. Descriptive and summary statistics were performed to describe the study participants according to their different characteristics. Additionally, a binary logistic regression analysis was conducted to test the relationship between DR and various risk factors. A P-value of $<0.05$ was considered to be significant.

\section{Results}

Out of 200 patients with diabetes, their age mean \pm SD was $50.74 \pm 13.51$ years, the duration of diabetes mellitus was $9.99 \pm 6.97$ years, their mean body mass index was 27.28 \pm 4.68 , the glycated hemoglobin $\%$ was $8.50 \pm 1.61$, the 
Table I Basic Characters of the Study Group (Mean \pm SD)

\begin{tabular}{|l|l|}
\hline Character & Mean \pm SD \\
\hline Age & $50.74 \pm 13.5 I$ \\
Duration of diabetes & $9.99 \pm 6.97$ \\
BMI & $27.28 \pm 4.68$ \\
The glycated hemoglobin & $8.50 \pm 1.61$ \\
Diet soda (cans/week) & $1.31 \pm 1.57$ \\
Artificial sweeteners (sachet/day) & $1.06 \pm 1.39$ \\
\hline
\end{tabular}

patients used to consume $1.31 \pm 1.57$ diet soda cans/week, and $1.06 \pm 1.39$ artificial sweeteners/sachet/day (Table 1).

In the current survey ( $49 \%$ women), diabetic retinopathy was found in 33\%, also in the present sample, $57 \%$ were obese, $53 \%$ hypertensive and the majority $(70 \%)$ were poorly controlled diabetes. Symptomatic hypoglycemia was reported in $20 \%, 52 \%$ were on oral hypoglycemic drugs and $48 \%$ were on both oral medications and insulin. In addition to that, smoking was found in $20 \%, 53 \%$ were on regular exercise, and a family history of diabetes was reported by $73 \%$ (Table 2 ).

In the present study, multiple regression analysis showed Diet soda consumption was positively associated with diabetic retinopathy, $\mathrm{HbA1c}$, duration of diabetes, and age (P-values, $0.043,0.030,0.008$, and 0.016), no association was found between diet soda consumption, BMI, and sex (P-values, 0.295, and 0.491). $\mathrm{R}=0.306$, $\mathrm{R}$ square $=0.093$, and standard

Table 2 Basic Characters of the Study Group (number\%)

\begin{tabular}{|l|l|}
\hline Character & No $\%$ \\
\hline $\begin{array}{l}\text { Sex } \\
\text { Women }\end{array}$ & $\begin{array}{l}98(49 \%) \\
102(51 \%)\end{array}$ \\
\hline Diabetic retinopathy & $66(33.0 \%)$ \\
\hline Peripheral neuropathy & $14(7.0 \%)$ \\
\hline Obesity & $114(57.0 \%)$ \\
\hline Hypertension & $106(53.0 \%)$ \\
\hline Poorly controlled diabetes & $140(70.0 \%)$ \\
\hline Symptomatic hypoglycemia in the last year & $40(20.0 \%)$ \\
\hline Medications & $\begin{array}{l}\text { Oral hypoglycemic drugs } \\
\text { Oral hypoglycemic agents and insulin }\end{array}$ \\
On regular exercise & $\begin{array}{l}104(52.0 \%) \\
96(48.0 \%)\end{array}$ \\
\hline Family history of diabetes & $106(53.0 \%)$ \\
\hline Smoking & $146(73.0 \%)$ \\
\hline
\end{tabular}

error of the estimate $=1.543$, the ANOVA showed a mean square of $7.4, \mathrm{~F}=3.10, \mathrm{P}$-value $=0.006$. Regarding artificial sweeteners, they were associated with BMI (P-value, 0.01); however, no association was found regarding age, sex, duration since the diagnosis of diabetes, HabAlc, and retinopathy (P-values, 0.401, 0.622, 0.569, 0.429, and 0.951). R for artificial sweeteners $=0.221$, R square $=0.049$, and standard error of the estimate $=1.397$, the ANOVA showed a mean square of 3.017, $\mathrm{F}=1.54$, P-value $=0.166$ (Tables 3 and 4).

\section{Discussion}

In the present study, $33 \%$ of the patients were suffering from diabetic retinopathy. The current observations were in line with a previous study in South Saudi Arabia, which reported a prevalence of $27.8 \%$. A registry-based study in the Kingdom of Saudi Arabia ${ }^{15}$ reported a prevalence of $19.7 \%$ and attributed the low rate of retinopathy to the lack of screening program so many patients may be missed. Regarding the association of diet soda and non-nutritive sweeteners with glycated hemoglobin, obesity, and diabetic retinopathy, we found a contradiction. Diet soda was associated with a higher $\mathrm{HbAlc}$ and diabetic retinopathy, while no association was found regarding obesity. The reverse holds for non-caloric flavor consumption (associated with obesity only). Our findings are in line with a previous study conducted among 609 patients with diabetes ${ }^{14}$ and found a two-fold increase in proliferative DR among those who consumed $>4$ bottles/week. Further previous studies reported the association of diet soda and artificial sweeteners with a high body mass index and cardiometabolic consequences. ${ }^{16,17}$ The association of diet soda and higher glycated hemoglobin has been reported by a study from the USA. ${ }^{18}$ Non-nutritive sweetener association with higher body mass index was reported in the United States and Australia. ${ }^{18,19}$ Reward inhibition at the ventrolateral prefrontal regions of the brain and adaptation to taste-calorie uncoupling are suggested. ${ }^{20}$ The association of NNS, diet soda, and demographic variables was inconsistent between studies. Ahmad et al reviewed the literature and found no association between NNS and HbAlc and in line with the current observations. $^{21}$

\section{The Gut Microbiota, and Taste Receptors Modulation by NNS as Drivers of Cardiometabolic Risk Factors}

The ecology of gut microbiota (which contains trillions of organisms) is essential for intestinal barrier integrity and the host immune system. Animal studies showed that NNS 
Table 3 The Relationship of Dirt Soda to Retinopathy, HbAlc, Age, Sex, and BMI, and the Duration Since the Diagnosis of Diabetes Mellitus

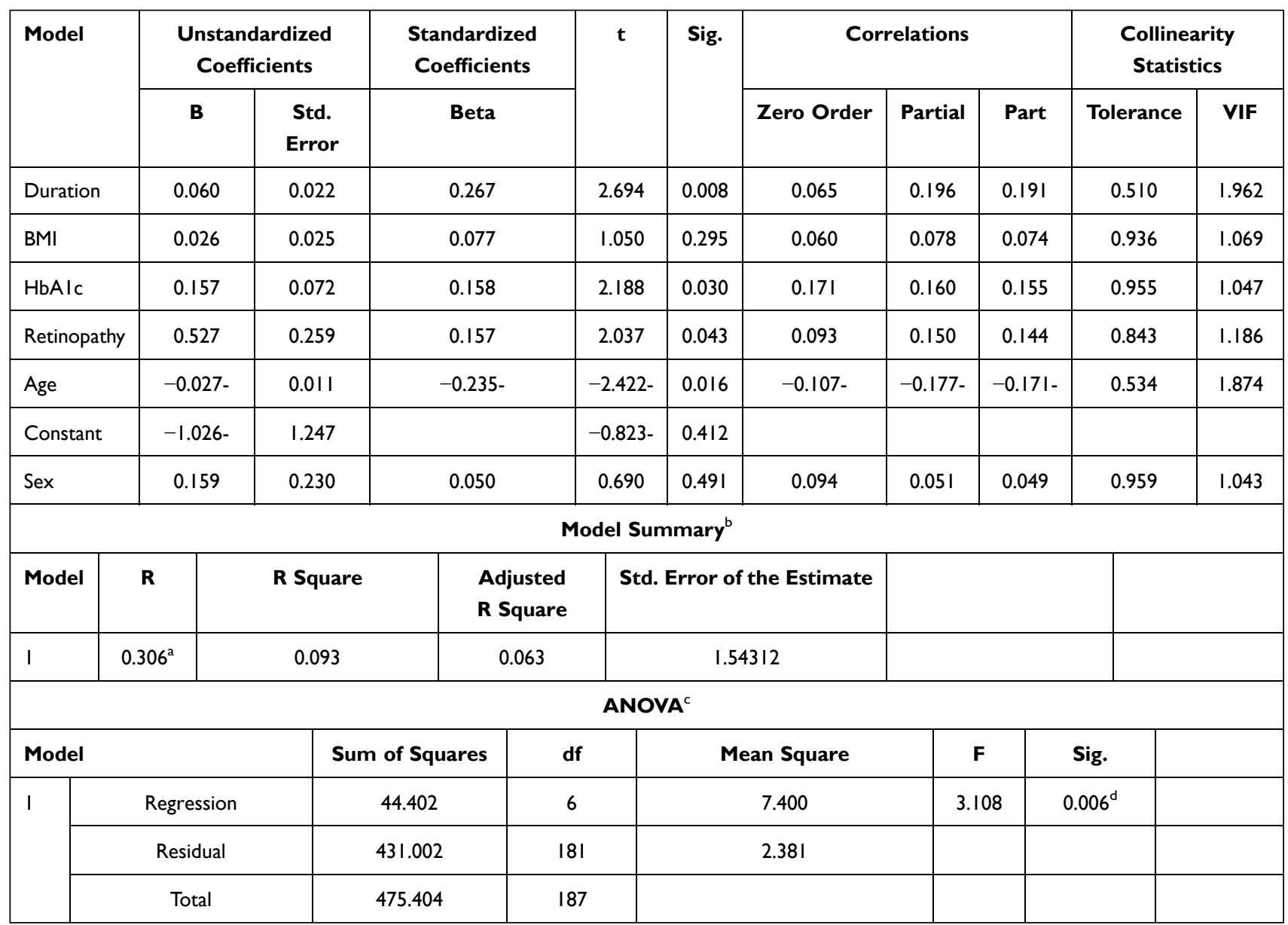

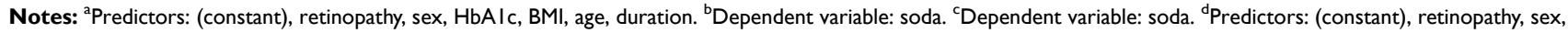
HbAlc, BMI, age, duration.

is bacteriostatic to the gut microbiota and shifting the Bacteroides/Firmicutes balance leading to inflammation, oxidative stress, and cardiometabolic diseases including obesity, insulin resistance, and diabetes. ${ }^{22}$ NNS-induced molecular crosstalk between the $\mathrm{G}$ protein-coupled receptors and insulin receptor was observed. ${ }^{23}$ A multitude of endocrine changes were observed through activation of taste receptors in the mouth, gastrointestinal tract, $\beta$ cells of the pancreas, and brain. ${ }^{24}$ Activating the bitter receptors might increase the appetite and food consumption increasing weight. ${ }^{25}$ On the other hand, authorities including FDA consider NNS safe if limited to acceptable daily intake (ADI), of note is that NNS is not uniform as aspartame and its degradation products are not contacting the microbiota. However, Potassium Acesulfame is absorbed and excreted in the urine and surprisingly it induced Firmicutes/A. muciniphila disruption despite no direct contact. ${ }^{26}$ A recent study used the ADI of aspartame and sucralose and found no alteration of the gut microbiome supporting the above findings. ${ }^{27}$ There is a big gap of knowledge regarding the mechanism through which NNS exerts its effects. Importantly, people may not realize the consumption of these products because they are widely available in many food and beverages. An interesting trial found that nearly half of the patients randomized for sucralose non-consumers showed the substance in their urine. The authors explained their findings by non-dietary sources including personal care products. ${ }^{28}$ Randomized controlled trials with a long follow-up period are needed to solve the issue; currently, it is wise to avoid Potassium Acesulfame and use Aspartame and Sucralose in the ADI doses. 
Table 4 The Relationship of Artificial Sweeteners to Retinopathy, HbAlc, Age, Sex, and BMI, and the Duration of Diabetes

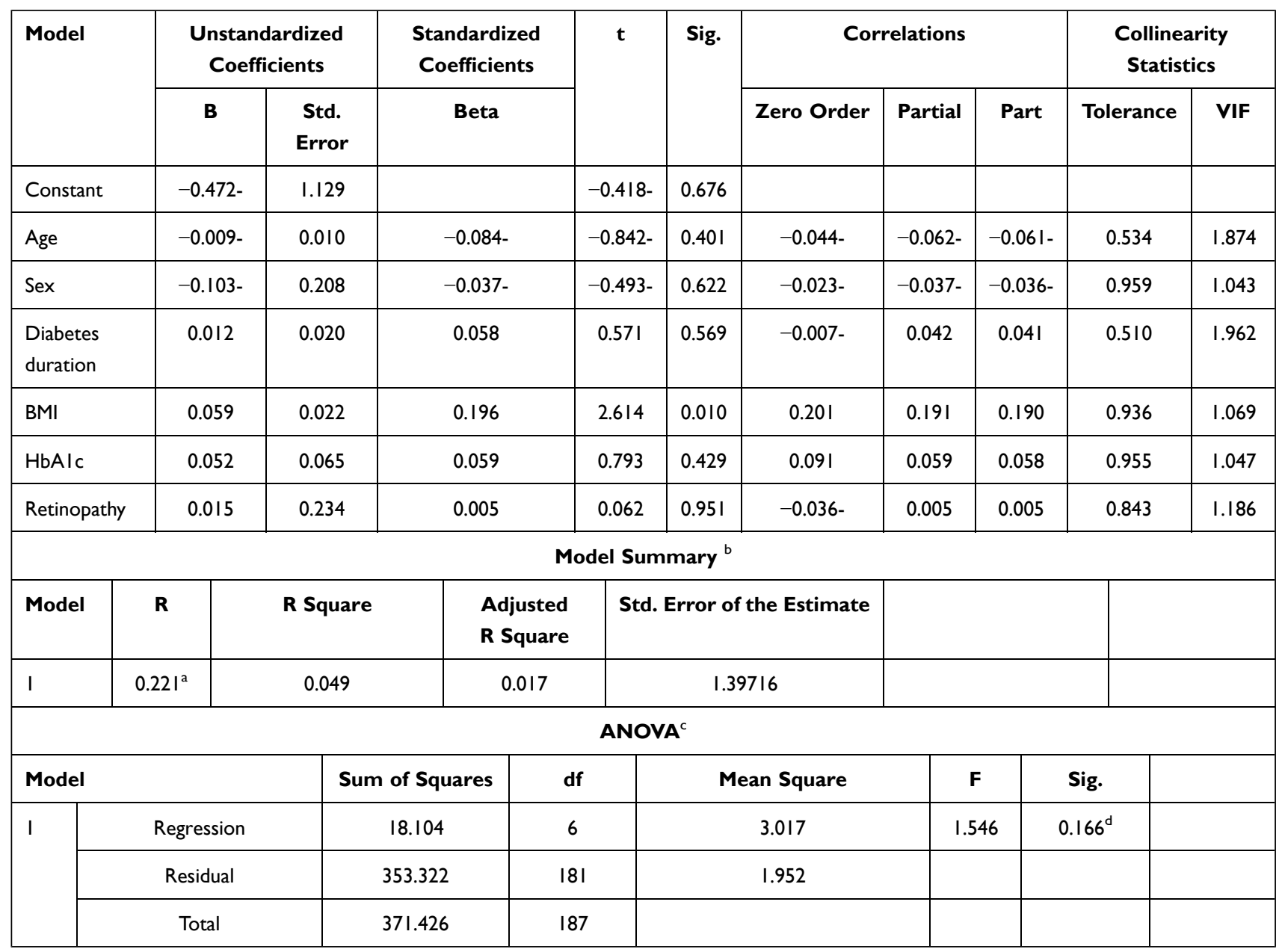

Notes: aPredictors: (constant), retinopathy, sex, HbAlc, BMI, age, duration. ${ }^{b}$ Dependent variable: sweeteners. ${ }^{~}$ Dependent variable: sweeteners. ${ }^{\mathrm{d}}$ Predictors: (constant), retinopathy, sex, HbAIc, BMI, age, duration.

\section{Conclusion}

Non-nutritive sweeteners were associated with obesity but not retinopathy or $\mathrm{HbAlc}$, while diet soda was associated with high glycated hemoglobin and diabetic retinopathy.

The study limitations were the small size of the study sample, the low consumption of Diet sugar-free carbonated soda beverage, non-caloric flavors, and the fact that the survey was conducted at a single tertiary center, so generalization to the whole Kingdom of Saudi Arabia cannot be insured.

\section{Abbreviations}

DR, diabetic retinopathy; BMI, body mass index; IRMA, intraretinal microvascular abnormalities; SPSS, the Statistical Package for Social Sciences.

\section{Data Sharing Statement}

All the data presented in this manuscript are available on request.

\section{Ethical Issues}

This study was conducted following the Declaration of Helsinki, the patient's privacy was secured and they were assured that the data will be used only for this survey. All the participants signed written informed consent, and the ethical committee of the University of Tabuk approved the research (ref. number, UT-93-1-2020, date, 27/1/2020).

\section{Acknowledgments}

The authors would like to acknowledge Dr. Ihab Farah, Assistant Professor of Statistics, Faculty of Applied Medical Sciences, Tabuk, Saudi Arabia for the substantial contribution to the data analysis.

\section{Author Contributions}

All authors made a significant contribution to the work reported, whether that is in the conception, study design, execution, acquisition of data, analysis, and interpretation, 
or in all these areas; took part in drafting, revising, or critically reviewing the article; gave final approval of the version to be published; have agreed on the journal to which the article has been submitted; and agree to be accountable for all aspects of the work.

\section{Disclosure}

The authors report no conflict of interest in this work.

\section{References}

1. IDF Diabetes Atlas. 9th ed. Brussels. Belgium: International Diabetes Federation; 2019 [last updated September 14, 2020]. Available from: https://www.idf.org/e-library/epidemiology-research/diabetes-atlas /159-idf-diabetes-atlas-ninth-edition-2019.html. Accessed February 5, 2021.

2. Ahmed RA, Khalil SN, Al-Qahtani MA. Diabetic retinopathy and the associated risk factors in diabetes type 2 patients in Abha, Saudi Arabia. J Fam Community Med. 2016;23(1):18-24. doi:10.4103/ 2230-8229.172225

3. Al-Rubeaan K, Youssef AM, Subhani SN, et al. Diabetic nephropathy and its risk factors in a society with a type 2 diabetes epidemic: a Saudi National Diabetes Registry-based study. PLoS One. 2014;9: e88956. doi:10.1371/journal.pone.0088956

4. Yau JW, Rogers SL, Kawasaki R, et al. Global prevalence and major risk factors of diabetic retinopathy. Diabetes Care. 2012;35:556-564. doi:10.2337/dc11-1909

5. Song P, Yu J, Chan KY, Theodoratou E, Rudan I. Prevalence, risk factors and burden of diabetic retinopathy in China: a systematic review and meta-analysis. $J$ Glob Health. 2018;8(1):010803. doi:10.7189/jogh.08.010803

6. Klein R, Klein BE, Moss SE, Cruickshanks KJ. The Wisconsin Epidemiologic Study of Diabetic Retinopathy: XVII. The 14-year incidence and progression of diabetic retinopathy and associated risk factors in type 1 diabetes. Ophthalmology. 1998;105 (10):1801-1815. doi:10.1016/S0161-6420(98)91020-X

7. Klein R, Lee KE, Knudtson MD, Gangnon RE, Klein BE. Changes in visual impairment prevalence by period of diagnosis of diabetes: the Wisconsin Epidemiologic Study of Diabetic Retinopathy. Ophthalmology. 2009;116(10):1937-1942. doi:10.1016/j. ophtha.2009.03.012

8. Zheng Y, He M, Congdon N. The worldwide epidemic of diabetic retinopathy. Indian J Ophthalmol. 2012;60(5):428-431. doi:10.4103/ 0301-4738.100542

9. Porwal P, Pachade S, Kokare M, et al. Diabetic retinopathy - segmentation and grading challenge. Med Image Anal. 2020;59:101561. PMID: 31671320. doi:10.1016/j.media.2019.101561

10. Rehan HS, Grover A, Hungin AP. Ambiguities in the guidelines for the management of arterial hypertension: Indian perspective with a call for global harmonization. Curr Hypertens Rep. 2017;19 (2):17. doi:10.1007/s11906-017-0715-4

11. Eskow CC, Oates TW. Dental implant survival and complication rate over 2 years for individuals with poorly controlled type 2 diabetes mellitus. Clin Implant Dent Relat Res. 2017;19(3):423-431. doi:10.1111/cid.12465

12. Shahid M, Shaibi GQ, Baines H, Garcia-Filion P, Gonzalez-Garcia Z, Olson M. Risk of hypoglycemia in youth with type 2 diabetes on insulin. $J$ Pediatr Endocrinol Metab. 2018;31(6):625-630. doi:10.1515/jpem-2018-0014

13. Smith W, Mitchell P, Reay EM, Webb K, Harvey PW. Validity and reproducibility of a self-administered food frequency questionnaire in older people. Aust N Z J Public Health. 1998;22:456-463. doi:10.1111/j.1467-842X.1998.tb01414.x
14. Fenwick EK, Gan AT, Man RE, et al. Diet soft drink is associated with increased odds of proliferative diabetic retinopathy. Clin Exp Ophthalmol. 2018;46(7):767-776. doi:10.1111/ceo.13154

15. Hajar S, Al Hazmi A, Wasli M, Mousa A, Rabiu M. Prevalence and causes of blindness and diabetic retinopathy in Southern Saudi Arabia. Saudi Med J. 2015;36(4):449-455. doi:10.15537/ smj.2015.4.10371

16. Wat N, Wong RL, Wong IY. Associations between diabetic retinopathy and systemic risk factors. Hong Kong Med J. 2016;22 (6):589-599. doi:10.12809/hkmj164869

17. Bernstein AM, de Koning L, Flint AJ, Rexrode KM, Willett WC. Soda consumption and the risk of stroke in men and women. $A m$ J Clin Nutr. 2012;95(5):1190-1199. doi:10.3945/ajen.111.030205

18. Mackenzie T, Brooks B, O'Connor G. Beverage intake, diabetes, and glucose control of adults in America. Ann Epidemiol. 2006;16 (9):688-691. PMID: $16458538 . \quad$ doi:10.1016/j. annepidem.2005.11.009

19. Hedrick VE, Passaro EM, Davy BM, You W, Zoellner JM. Characterization of non-nutritive sweetener intake in rural Southwest Virginian adults living in a health-disparate region. Nutrients. 2017;9(7):757. PMID: 28708096; PMCID: PMC5537871. doi:10.3390/nu9070757

20. Grech A, Kam CO, Gemming L, Rangan A. Diet-quality and socio-demographic factors associated with non-nutritive sweetener use in the Australian population. Nutrients. 2018;10(7):833. PMID: 29954097; PMCID: PMC6073373. doi:10.3390/nu10070833

21. Ahmad SY, Azad MB, Friel J, MacKay D. Recent evidence for the effects of nonnutritive sweeteners on glycaemic control. Curr Opin Clin Nutr Metab Care. 2019;22(4):278-283. PMID: 31033578. doi:10.1097/MCO.0000000000000566

22. Wang QP, Browman D, Herzog H, Neely GG. Non-nutritive sweeteners possess a bacteriostatic effect and alter gut microbiota in mice. PLoS One. 2018;13(7):e0199080. doi:10.1371/journal.pone.0199080

23. Liauchonak I, Qorri B, Dawoud F, Riat Y, Szewczuk MR. Nonnutritive sweeteners and their implications on the development of metabolic syndrome. Nutrients. 2019;11(3):644. doi:10.3390/ nu11030644

24. Rother KI, Conway EM, Sylvetsky AC. How non-nutritive sweeteners influence hormones and health. Trends Endocrinol Metab. 2018;29(7):455-467. doi:10.1016/j.tem.2018.04.010

25. Turner A, Veysey M, Keely S, Scarlett CJ, Lucock M, Beckett EL. Intense sweeteners, taste receptors and the gut microbiome: a metabolic health perspective. Int $J$ Environ Res Public Health. 2020;17(11):4094. PMID: 32521750; PMCID: PMC7312722. doi:10.3390/ijerph17114094

26. Plaza-Diaz J, Pastor-Villaescusa B, Rueda-Robles A, Abadia-Molina F, Ruiz-Ojeda FJ. Plausible biological interactions of low- and non-calorie sweeteners with the intestinal microbiota: an update of recent studies. Nutrients. 2020;12(4):1153. doi:10.3390/nu12041153

27. Ahmad SY, Friel J, Mackay D. The effects of non-nutritive artificial sweeteners, aspartame and sucralose, on the gut microbiome in healthy adults: secondary outcomes of a randomized double-blinded crossover clinical trial. Nutrients. 2020;12(11):3408. PMID: 33171964; PMCID: PMC7694690. doi:10.3390/nu12113408

28. Sylvetsky AC, Walter PJ, Garraffo HM, Robien K, Rother KI. Widespread sucralose exposure in a randomized clinical trial in healthy young adults. Am J Clin Nutr. 2017;105(4):820-823. doi:10.3945/ajen.116.144402 


\section{Publish your work in this journal}

Diabetes, Metabolic Syndrome and Obesity: Targets and Therapy is an international, peer-reviewed open-access journal committed to the rapid publication of the latest laboratory and clinical findings in the fields of diabetes, metabolic syndrome and obesity research. Original research, review, case reports, hypothesis formation, expert opinion and commentaries are all considered for publication. The manuscript management system is completely online and includes a very quick and fair peer-review system, which is all easy to use. Visit http://www.dovepress.com/testimonials.php to read real quotes from published authors.

Submit your manuscript here: https://www.dovepress.com/diabetes-metabolic-syndrome-and-obesity-targets-and-therapy-journal 